\title{
Spillover Effect on Families Derived from Environmental Education for Children
}

\author{
Ai Hiramatsu1, Kiyo Kurisu', Hiroshi Nakamura², Shuichi Teraki ${ }^{3}$, Keisuke Hanaki ${ }^{4}$ \\ ${ }^{1}$ Research Center for Advanced Science and Technology, The University of Tokyo, Tokyo, Japan \\ ${ }^{2}$ Global Environmental Forum, Tokyo, Japan \\ ${ }^{3}$ Department of Education, Toyo University, Tokyo, Japan \\ ${ }^{4}$ Department of Urban Engineering, The University of Tokyo, Tokyo, Japan \\ Email: ai@env.t.u-tokyo.ac.jp, nakamura@gef.or.jp, kiyo@env.t.u-tokyo.ac.jp, teraki@toyo.jp, \\ hanaki@env.t.u-tokyo.ac.jp
}

Received 10 April 2014; revised 8 May 2014; accepted 15 May 2014

Copyright (C) 2014 by authors and Scientific Research Publishing Inc.

This work is licensed under the Creative Commons Attribution International License (CC BY).

http://creativecommons.org/licenses/by/4.0/

(c) (i) Open Access

\begin{abstract}
Facing the challenge of global warming, greater importance has been placed on learning energy and environment in schools and the energy-saving behaviors of children and their families are encouraged. The authors implemented energy environmental education programs with visualization in elementary and junior high schools, and surveyed changes in the awareness and behavior of children and their families. As for children, the results showed that the programs increased the awareness of effectiveness, while almost no change was observed in other factors. The psychological factors impacting intention and behavior in children were attitude, expectations from parents and expansion of interest. Indicating spillover effect on families derived from education of children, psychological factors and behavior of parents were improved. Awareness of effectiveness and behavior of children had significant effects to the most psychological factors of parents, leading to intentional and behavioral change. Furthermore, behavior of parents got influenced by expectations from children. It was also indicated that the higher the awareness of the child is, the greater the spillover effect on the family as a result of education is.
\end{abstract}

\section{Keywords}

School Education, Energy-Saving, Structural Equation Modeling (SEM), Psychological Factors, Awareness and Behavior

\section{Introduction}

Environment-friendly behaviors (EBs) have increasingly been encouraged, and greater importance is being plac- 
ed on learning energy and environment, which has been clearly involved in the recent curriculum guidelines for schools in Japan [1] [2]. EBs are strongly influenced not only by the acquisition of knowledge but also by direct experiences. The process of "visualization", by which the effects of one's actions can be seen and confirmed, has been shown to be effective [3] [4]. Experience-based participatory lessons, however, are still not commonly included in school education [5]-[7]. Furthermore, the benefits of environmental education programs have not been clearly evaluated, and there has been little consideration of curriculum content that will lead to EBs not only by students, but also within their families [8].

When it comes to EBs of individuals, parents' behaviors can influence their children's behaviors within a family, and children's habits and values can be particularly influenced [9]-[11]. On the other hand, children's influence on their parents has not been well-evaluated. It is still unknown the extent to which children impact their parents' awareness and behaviors through things they learn at school and take home.

Various models have been proposed for the psychological process of behaviors including EBs. Existing theories include the Theory of Reasoned Action (TRA) [12], which expresses the structure of psychological factors such as attitude, subjective norm, intention and behavior; the Theory of Planned Behavior (TPB) [13], which develops this to include perceived behavioral control (PBC); Norm Activation Theory [14], which takes into consideration of morality; and Value-Belief-Norm Theory [15], which focuses on values, along with various models for their application [16]-[19]. In terms of EBs, a gap exists between "attitude" and "behavior". For example, even someone thinks that global warming is a serious problem, he or she actually takes no specific action. Categorizing and analyzing the psychological factors behind this allows more appropriate mechanisms leading to behaviors to be ascertained, and has the potential to promote behaviors [19] [20].

Based on the above, the authors implemented a program of experience-based education relating to energy and the environment with visualization in elementary and junior high schools. Then the behavioral and awareness changes among the children as well as their families were investigated, considering the spillover effect in families by the environmental education of children. We tried to evaluate the relationships between the children's psychological factors and those of their parents by structural equation modelling.

\section{Material and Methods}

\subsection{Implementation of an Experience-Based Environmental Education Program with Visualization}

Between October 2011 and January 2012, we implemented a program of energy-related environmental education designed to lead to new awareness within the home. The program was implemented in the integrated study periods and individual subject (science) lessons at elementary and junior high schools in one of wards (Bunkyo) of Tokyo, Japan. The program was implemented in consideration of the priorities within curriculum guidelines, but focused on specific activities that included visualization, and aimed to involve children in problem solving related to issues familiar in their daily lives. The elementary and junior high schools where the project was implemented are shown in Table 1.

The visualization took the form of using a "watt checker", which is a piece of apparatus that enables electricity use to be measured in real time, in experiments to measure how much electricity is used by familiar items, and the use of an "energy-saving navigator", which allowed students to pursue changes in the electricity use through energy-saving behaviors. Students were encouraged to think about issues such as the use of lighting in school. In addition to this, in order to involve the entire family, students were asked to read their own family electricity meter and implement energy savings at home. The energy-saving navigator was put to the power distribution board, and displayed the amount and price of electricity use in real time, allowing visual confirmation of how much electric power use changes depending on their behaviors (Figure 1). Plugging domestic electrical appliances into power sockets via the watt checker allowed real-time visual confirmation of how much power is consumed by the item while on standby and in use (Figure 2).

\subsection{Survey of Changes in Awareness and Behavior}

In order to analyze the children's behavioral change as a result of the education program, a questionnaire survey was conducted for the children and their families (parents/guardians). The questions were prepared based on the TPB and the further developed method of Hayabuchi [20]. In addition to the questions about values of energy 
Table 1. Outline of energy-related environmental education implemented in elementary and junior high schools.

\begin{tabular}{|c|c|c|c|c|c|}
\hline \multirow{2}{*}{ School } & \multirow{2}{*}{ Grade $^{*}$} & \multirow{2}{*}{ Subject } & \multirow{2}{*}{ Contents } & \multicolumn{2}{|c|}{ No. of } \\
\hline & & & & Students & Classes \\
\hline $\mathrm{X}$ & $E-5^{\text {th }}$ & $\begin{array}{l}\text { Integrated } \\
\text { study }\end{array}$ & $\begin{array}{l}\text { - Use of energy-saving navigator to look at how lighting is used in } \\
\text { the classroom } \\
\text { - Survey of family electrical products (reading family electricity } \\
\text { meter) }\end{array}$ & 52 & 4 \\
\hline $\mathrm{Y}$ & $\mathrm{J}-2^{\text {nd }}$ & $\begin{array}{l}\text { Integrated } \\
\text { study }\end{array}$ & $\begin{array}{l}\text { - } \quad \text { LED lighting } \\
\text { - Use of watt-checker to measure energy-saving benefits of a range } \\
\text { of equipment } \\
\text { - Survey of family electrical products (reading family electricity } \\
\text { meter) }\end{array}$ & 38 & 2 \\
\hline Z & $\mathrm{J}-2^{\text {nd }}$ & Science & $\begin{array}{l}\text { - Use of energy-saving navigator to look at how lighting is used } \\
\text { in the classroom } \\
\text { - Survey of family electrical products (reading family electricity } \\
\text { meter) }\end{array}$ & 85 & 3 \\
\hline
\end{tabular}

"E: Elementary school; J: Junior high school.

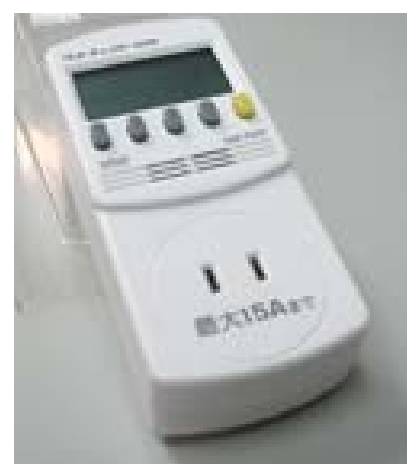

Figure 1. Watt checker.
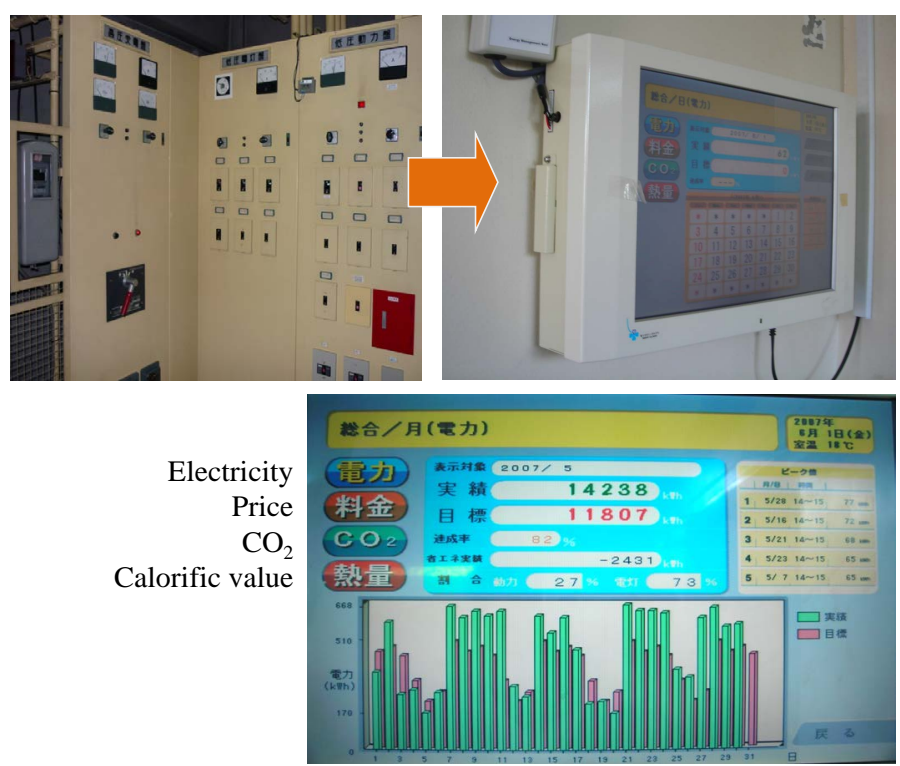

Figure 2. Energy-saving navigator. Power consumption data are sent from the power distribution board (top left) to the energy-saving navigator, and displayed on the monitor (top right). An example of the monitor display (bottom). 
savings, the questions for awareness of effectiveness were prepared, considering the realization of energy-saving benefits as a result of seeing saved electricity. Details are given in Table 2. The questions were the same for children and their parents, except one question asking about values of energy savings (p3-1). Furthermore, in regard to subjective norms $(\mathrm{s} / \mathrm{p}-4,5)$, children were asked about the expectations from their parents, schoolteachers and friends, while parents were asked about the expectations from their children, neighbors, and friends.

The children's perceptions were surveyed three times in order to analyze changes in their awareness and behaviors. It was carried out first prior to the environmental education implemented, then immediately afterward, and again a month later to evaluate the continuity. The questionnaire sheets were distributed to all the children participating the classes by either the responsible person for the program or by the class teacher, and the children were asked to fill and return them then and there. Each question was asked using 5-item Likert scale: "strongly think so", "think so", "slightly think so”, "slightly do not think so”, and "do not think so”, while "always”, “often”, "sometimes”, "rarely”, and "never" were used for the question about the behavior itself. These answers were converted into 5 to 1 for the statistical analysis.

In the case of the families, the questionnaire sheets were passed via their children, distributed by the teacher after the program completed. The parents were asked to complete the questionnaire at home, and the sheets were collected and returned to the teachers by the children. The parents were asked once about the level of "change" by the program, using six-item Likert scale: "I get strongly to think so", "I get to think so", "I get slightly to think so", "no change”, "I get slightly not to think so”, "I get not to think so”, while the word of "conduct” was used instead of "think" for asking the behavior change. The values +3 to -2 ( 0 : no change) were applied to the answers for the analysis. The parents were also asked the extent to which energy-saving behavior had specifically changed since before the education program. Besides, they were asked about the increase within the family in discussions, concerns, or behaviors relating to global warming; if there had been changes, the reasons were also asked.

The answers gained both from the children and their parents were used for the analysis, giving 116 valid responses (with a response rate of 66\%). In addition to the basic statistical analyses, we applied structural equation modeling (SEM) to investigate how awareness and behavior in the children had impacted their families, using 105 samples in which there were zero missing values from either the parent or the child. For the SEM, SPSS Amos Ver. 20 (IBM Co., USA) was used.

\section{Results and Discussion}

\subsection{Changes in the Children}

In contradiction to the assumption, almost no significant changes were observed in the awareness and behavior of the children before and after the education program. While a slight increase in all categories was observed just after the program, it fell again in almost all categories a month later. The only area in which a significant increase was seen as a result of learning was in “AE: awareness of effectiveness”, which rose from 3.83 (prior) to 4.01 (immediately afterward) and 3.91 (a month later). It indicates that this effect was achieved by a quantitative understanding of the reduction in energy use achieved by energy-saving behaviors through visualization, and a consequent realization of the benefits.

Figure 3 shows the average figures for awareness and behavior in the children just after the program. Higher values were seen in “AT: attitude”, “AC: awareness of consequences” and “AE: awareness of effectiveness”. In contrast, "PBC1: perceived behavioral control (perception of easiness to conduct the behavior)" and "PN: personal norm" showed lower values. The fact that there was almost no change post-learning indicated that the psychological state of the children is quite stable and not so influenced by outside forces. It is obviously important to note that in the year of this study the occurrence of the Great Eastern Japan Earthquake Disaster had already resulted in strong calls for energy-saving measures, and it is likely that the children's awareness of power saving was higher than it would have been in other years. There is also the possibility that "power-saving fatigue" occurred in some cases and there were no rooms to accept additional encouragements.

\subsection{Changes in Parents}

Of the questionnaires sent to the families, $86.5 \%$ were completed by mothers, $10.6 \%$ by fathers, and $2.9 \%$ by grandmothers. In terms of changes to the awareness/behavior of parents, more than one point rise was observed 
Table 2. Details of questions and their focus of analysis.

\begin{tabular}{|c|c|c|c|}
\hline \multicolumn{2}{|c|}{ Question ID } & \multirow{2}{*}{ Target $^{*}$} & \multirow{2}{*}{ Details of question } \\
\hline Child & Parent & & \\
\hline s1 & $\mathrm{p} 1$ & Behavior & Do you currently conduct energy-saving behaviors? \\
\hline s2 & p2 & Intention & Do you have intention to conduct energy-saving behaviors? \\
\hline- & p3-1 & VES1 & Do you think energy-saving behaviors are valuable? (Parents only) \\
\hline s3-2 & p3-2 & VES2 & Do you think energy-saving behaviors are useful? \\
\hline s3-3 & p3-3 & VES3 & Do you think energy-saving behaviors are a good thing? \\
\hline s4 & $\mathrm{p} 4$ & SN_P/SN_C & Do you think your [family (s4)/child (p4)] expects you to conduct energy-saving behaviors? \\
\hline s5 & p5 & SN_F & $\begin{array}{c}\text { Do you think your [school teachers and friends (s5)/friends and neighbors (p5)] } \\
\text { expect you to take energy-saving measures? }\end{array}$ \\
\hline s6 & p6 & PBC1 & Is it easy for you to take energy-saving measures? \\
\hline s7 & p7 & PBC2 & Could you take energy-saving measures if you wished to? \\
\hline s8 & p8 & $\mathrm{PN}$ & Do you feel guilty about using electricity? \\
\hline s9 & p9 & $\mathrm{R}$ & Do you feel obliged to take energy-saving measures? \\
\hline s10 & p10 & AT & Do you think that global warming is a serious problem? \\
\hline s11 & p11 & $\mathrm{AC}$ & $\begin{array}{l}\text { Do you think that energy-saving behavior is important in preventing } \\
\text { global warming, even to a minor extent? }\end{array}$ \\
\hline s12 & $\mathrm{p} 12$ & $\mathrm{AE}$ & Do you believe that energy-saving behavior can reduce the amount of electricity you use? \\
\hline s13 & p13 & EI & Do you wish to know more about ways to prevent global warming and save energy? \\
\hline
\end{tabular}

"VES: Values; SN: Subjective Norm; PBC: Perceived Behavior Control; PN: Personal Norm; R: Responsibility; AT: Attitude; AC: Awareness of Consequences; AE: Awareness of Effectiveness; EI: Expansion of Interest.

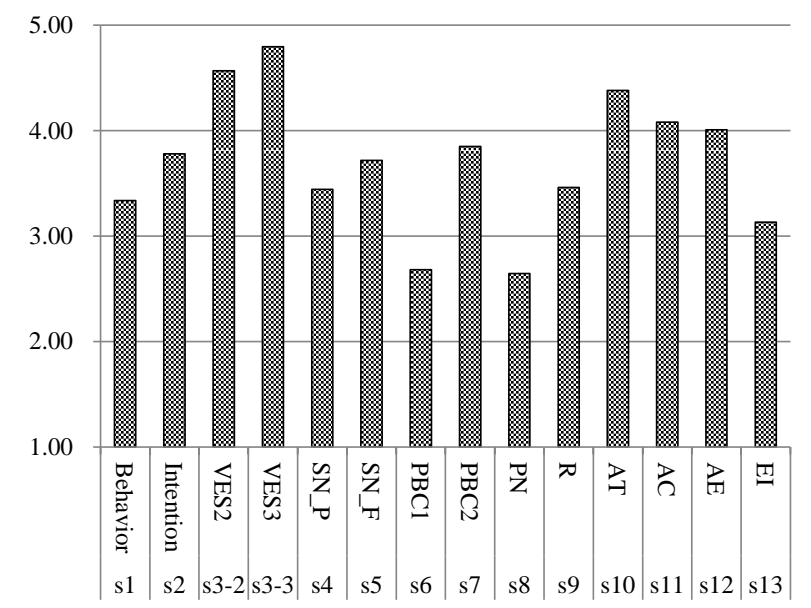

Figure 3. Post-learning awareness and behavior among children.

in most categories after the program (Figure 4). In particular, higher "VES: values” and “AE: awareness of effectiveness" indicated that the benefits of visualization extend not only to children but also to their parents. In terms of subjective norms, while little change was noted in "SN_F: perception about the expectations of neighbors and friends", the significant rise in "SN_P: perception about the expectations of children” was observed. The significant rise of SN_P indicated that the education was effectively communicated from children to their parents, by children involving in their parents in homework (reading electricity meter, etc.).

Checking the parents' individual behavior change (Figure 5, Table 3), increasing tendency was observed in all behaviors, particularly in "Light”, “A/C”, “TV”, and "PC”, all of which showed more than one point increase after the program. The rate of behavior to select the environment-friendly products with eco-labels is usually low [21], but in this study a comparable level of change was observed in "Ecomark" to "Fridge" and water saving through "Shower" and "Laundry". 


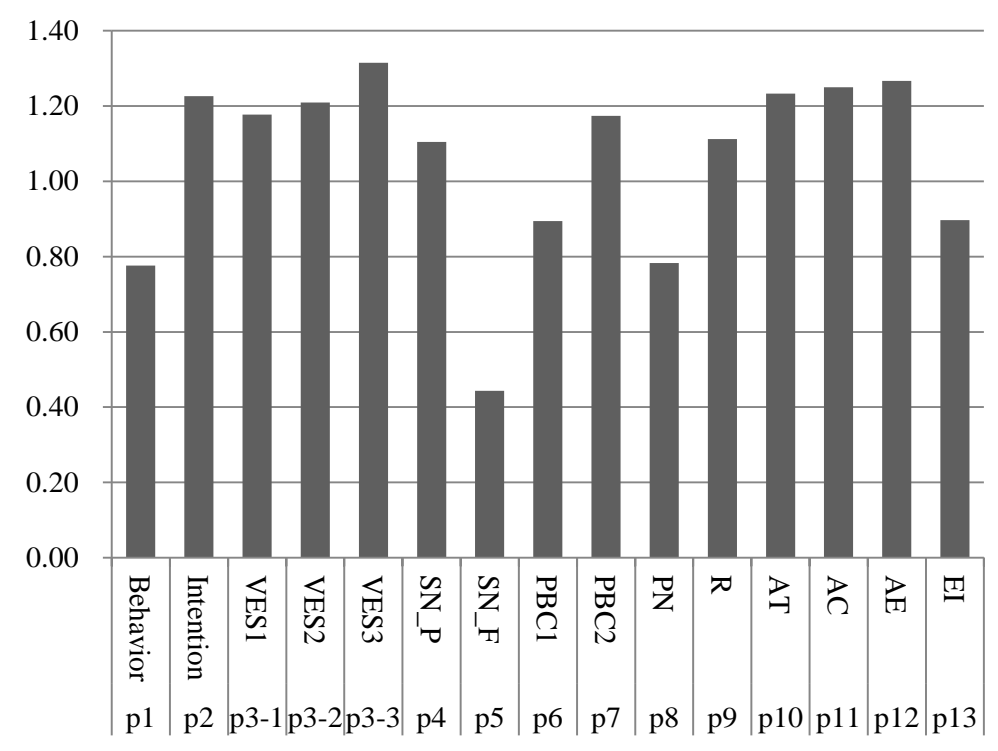

Figure 4. Post-learning changes in awareness and behavior among parents (no change $=0$ ).

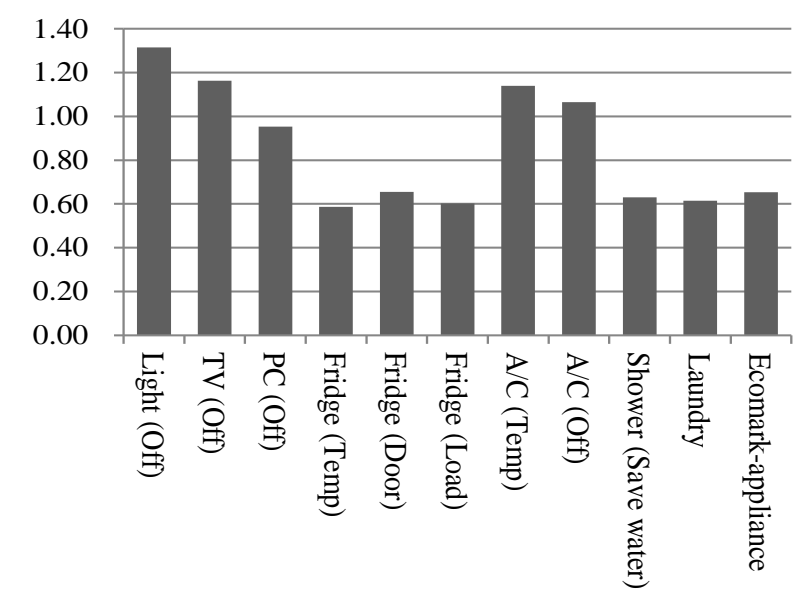

Figure 5. Specific changes to level of parents' behavior subsequent to education program.

Table 3. List of specific questions relating to energy-saving behavior.

\begin{tabular}{cc}
\hline Short description & Details \\
\hline Light (Off) & Tuning off lights in empty rooms \\
TV (Off) & Turning off the TV when people are not watching it \\
PC (Off) & Turning off the PC when people are not using it \\
Fridge (Temp) & Using a lower setting in the refrigerator compartment \\
Fridge (Door) & Reducing opening and closing the door of the refrigerator \\
Fridge (Load) & Avoiding overloading the refrigerator \\
A/C (Temp) & Adjusting the temperature of the air conditioner \\
A/C (Off) & Shortening the time of using air conditioner \\
Shower (Save water) & Taking shorter showers \\
Laundry & Cutting down on the frequency of washing clothes \\
Ecomark & Buying eco-mark-appliances \\
\hline
\end{tabular}


During the education program, not of all these behaviors were directly picked up, but it is indicated that checking electrical use and encouragement by children would have a spillover effect on other various energysaving behaviors.

The results of increase in discussions, concerns, and behaviors related to global warming within the family since the program started are shown in Figures 6-8.

In terms of "discussions" (Figure 6), 64\% of families said that they had already discussed the issue (no change), and $28 \%$ said that they had no discussion, while $7 \%$ of families reported that discussions had increased subsequent to the program. The most common reasons for discussion increase were an increased interest in the child(ren), the opportunity to use an electricity meter at home, and the benefits of energy-saving behaviors told by their child(ren).

Only 3.4\% of families responded that their concerns in global warming had increased, indicating that most the families had an existing interest in the topic. Families reporting a change commonly gave an increase in concerns/behaviors by the child(ren), or the benefits told by their child(ren), as the reason for the change.

In response to their behaviors in regard to global warming, $11.2 \%$ of families reported a rise in activity. Of the remaining families, $77.6 \%$ had been engaged in some activities prior to the program, while $11.2 \%$ responded that they were not engaged in any particular activities to prevent global warming. The most common reason for an increase in behavior was an increase in the child(ren)'s concerns about global warming, followed by an increase in the behaviors of the child(ren). In comparison with other categories, the impact of the benefits told by the child(ren) appeared lower.

The effect of visualization would be seen in the "assignment of reading electricity meter", but the changes in the children's concerns and behaviors had much greater impacts on the parents.

\subsection{Spillover Effect on Families of the Environmental Education for Children}

The correlations between the children's states just after the program and the parents' changes were calculated, and the statistically significant correlations $(\mathrm{p}<0.05)$ are shown in Table 4 . The results show that the awareness and behavior of children is related to various increases in awareness among parents/guardians, including intention, values related to energy savings, behavioral control, responsibility, attitude to the environment, awareness of effectiveness, etc. Of these, a significant correlation can be seen between awareness of effectiveness and the level of behavior implementation in children and many changes in awareness among parents/guardians, indicating that where children become aware of a benefit and behave accordingly, there is a stronger educational benefit to the parent/guardian as well.

In reference to the correlation coefficients, the structural model expressing the relationships between the children's and parents' variables were constructed by SEM. Figure 9 shows the significant model finally obtained. Each endogenous variable, which is explained by the other variables, has the error term, but to avoid excessive complexity, those have been omitted from the diagram. The model is usually evaluated by model fit indexes; CFI (Comparative Fit Index) ranges between 0 and 1, with higher values indicating better fit. CFI is quite stable and most widely used index. CFI values above 0.90 are usually associated with a good model fit; RMSEA

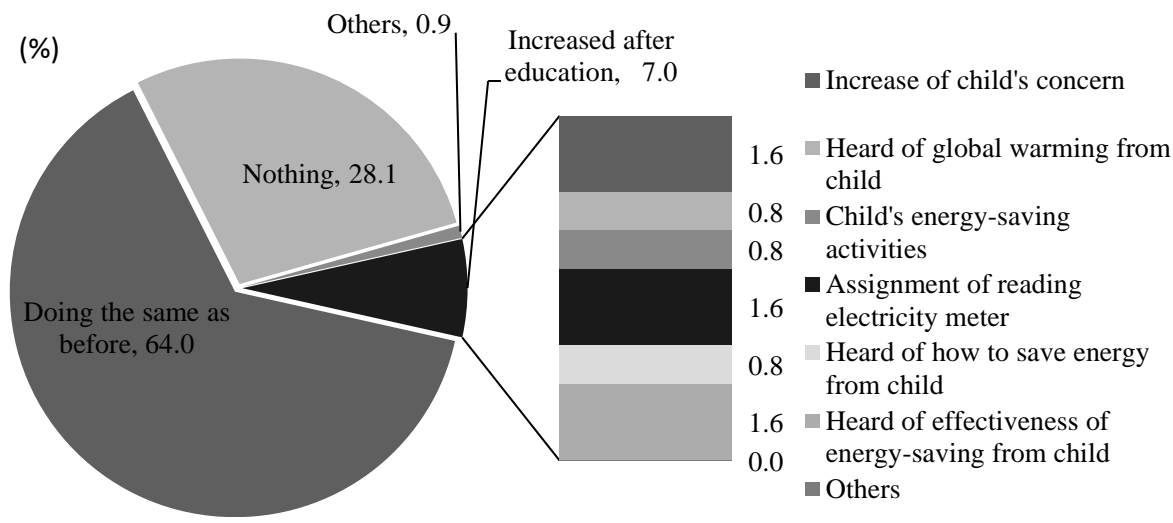

Figure 6. Rate of change and reason for increase after education: Topic of global warming. 


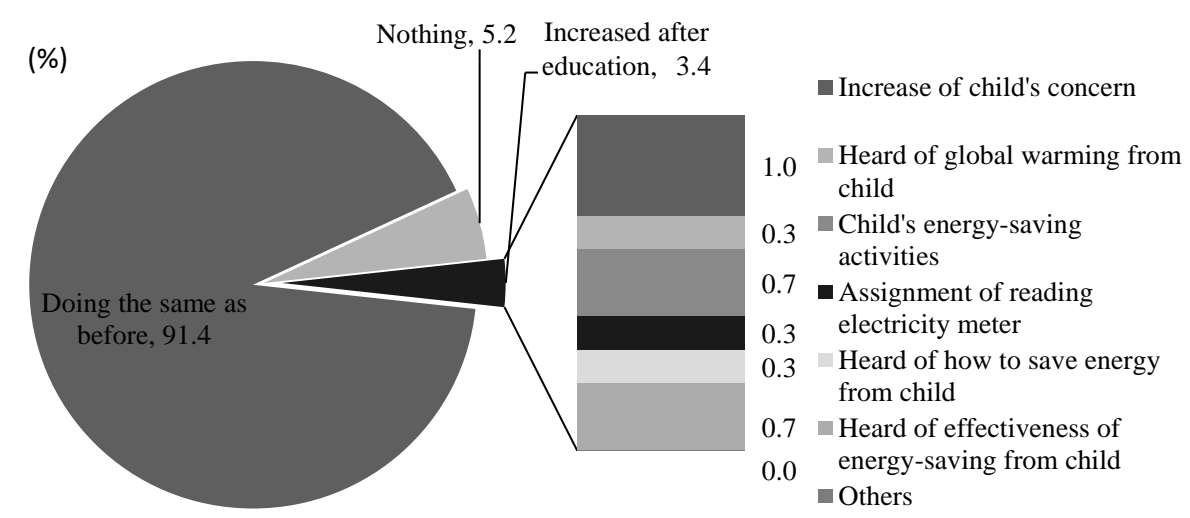

Figure 7. Rate of change and reason for increase after education: Concern for global warming.

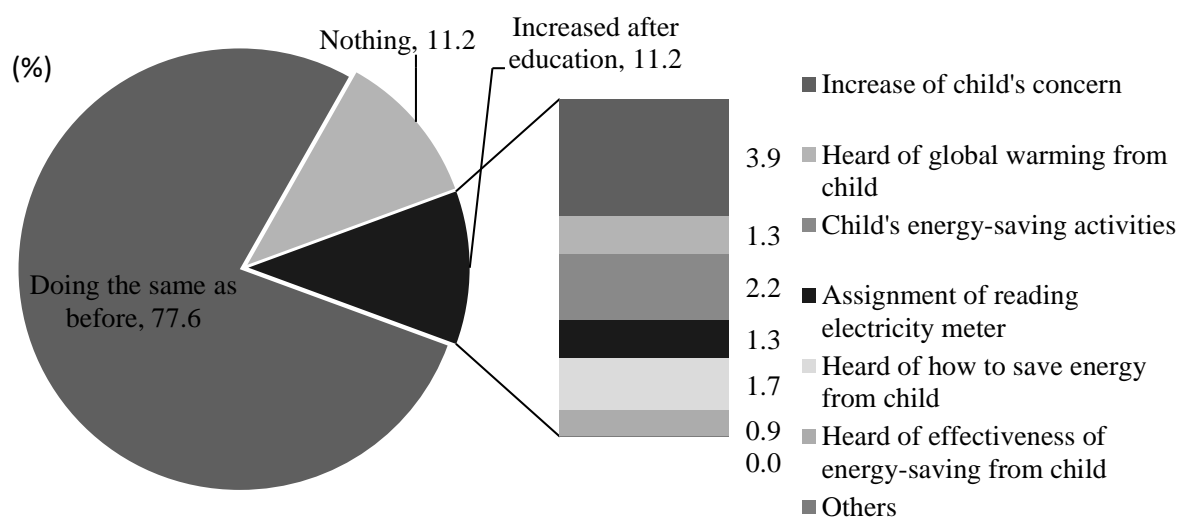

Figure 8. Rate of change and reason for increase after education: Action for preventing global warming.

Table 4. Correlation coefficient matrix between children's and parents' variables $(\mathrm{p}<0.05)$.

\begin{tabular}{|c|c|c|c|c|c|}
\hline \multicolumn{6}{|c|}{ Child } \\
\hline \multicolumn{2}{|c|}{ Parents } & s1 & s4 & s12 & s13 \\
\hline & & & & & \\
\hline p2 & Intention & - & 0.215 & 0.207 & - \\
\hline p3-1 & VES1 & - & - & 0.294 & - \\
\hline p3-2 & VES2 & - & - & 0.247 & - \\
\hline p3-3 & VES3 & - & - & 0.252 & - \\
\hline $\mathrm{p} 4$ & SN_C & 0.210 & - & - & 0.204 \\
\hline p7 & PBC2 & - & -0.213 & 0.264 & - \\
\hline p9 & $\mathrm{R}$ & 0.223 & - & 0.200 & - \\
\hline p10 & $\mathrm{AT}$ & 0.248 & - & 0.206 & - \\
\hline p12 & $\mathrm{AE}$ & - & - & 0.217 & - \\
\hline p13 & EI & 0.204 & - & - & - \\
\hline
\end{tabular}

(Root Mean Square Error of Approximation) is also widely used index. Lower RMSEA value (especially below 0.08) indicates better fit. The model shown in Figure 9 gives a little bit higher RMSEA value (=0.093), but the acceptable CFI (=0.91). Based on the model fit indexes, the overall model appears to have achieved a good fit.

Focusing on the children's intention (s-intention), it is influenced by expansion of interest $(\mathrm{s}-\mathrm{EI}=0.41)$ and the parents' expectation (SN_P =0.36), as well as the attitude (s-AT =0.18). The children's behavior (s-behavior) is also directly influenced by SN_P $(0.27)$, as well as the intention (s-intention $=0.36)$. The parents’ percep- 


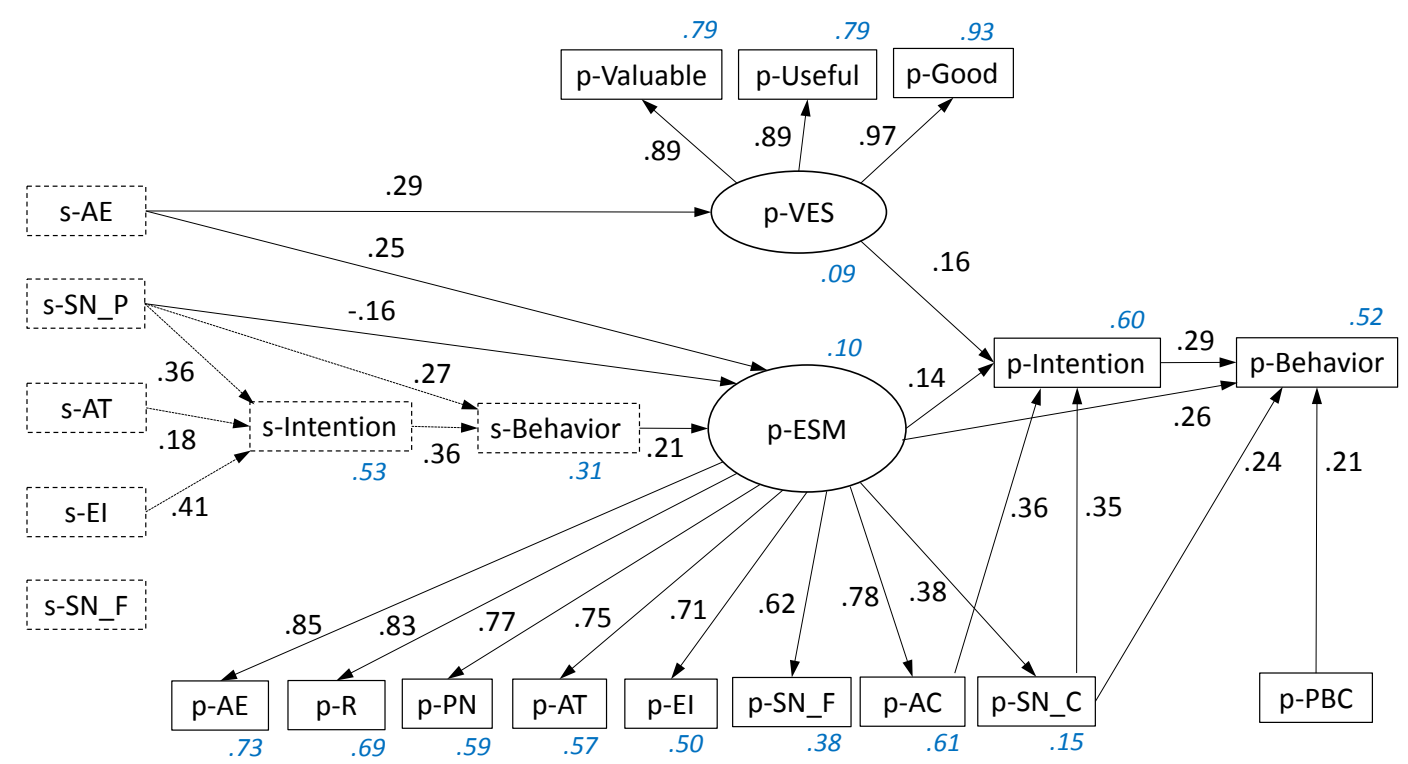

Figure 9. SEM of a spillover effect on parents derived from the environmental education of children (Italic: $\mathrm{R}^{2}$ ) (Standardized coefficients, $\mathrm{CMIN} / \mathrm{DF}=1.909, \mathrm{GFI}=0.824, \mathrm{AGFI}=0.743, \mathrm{CFI}=0.910, \mathrm{RAMSEA}=0.093$ ).

tion changes were compiled into two latent variables, namely "p-VES" and "p-ESM". "p-VES: Value of EnergySaving" was the latent variable behind the VES-1 to -3, which represented the change of value evaluation about the energy saving behaviors. "p-ESM: Energy-Saving Mind" was the latent variable representing most the psychological factor changes especially in the area of awareness of effectiveness ( $\mathrm{p}-\mathrm{AE}=0.85$ ), responsibility ( $\mathrm{p}-\mathrm{R}$ $=0.83)$, awareness of consequences ( $\mathrm{p}-\mathrm{AC}=0.78$ ), and personal norm $(\mathrm{p}-\mathrm{PN}=0.77)$.

The significant effect of children's behavior (s-Behavior) on the parents' perception improvement (p-ESM) was observed (0.21). Besides, the children's awareness of effectiveness (s-AE) had the significantly positive effects both on the p-VES (0.29) and p-ESM (0.25). The negative impact of s-SN_p on the p-ESM (-0.16) means that the parents whose children felt higher pressure from the parents were difficult to change their perceptions.

The parents intention change (p-Intention) was determined not only by p-VES (0.16) and p-ESM (0.14), but also directly by p-AC (0.36) and p-SN_C (0.35). The following behavioral change (p-Behavior) was determined by the intentional change (p-Intention $=0.29)$ and $\mathrm{p}-\mathrm{PBC}(0.21)$, which is consistent with the TPB model. Besides, in our model, the direct effects of p-ESM (0.26) and p-SN_C $(0.24)$ on the p-Behavior were observed. The expectations from children (p-SN_C) were not completely involved in the parents' holistic perception (p-ESM), but separately had the significant effects on the parents' intentional and behavioral change itself. Large impact of subjective norm (SN) on intention and behavior has been reported in many studies [22] [23] and also in Japan [20]. In our model, we separately considered the expectations from children and other surrounding people like friends and teachers. It indicated that parents got more influenced from their children than from close adults, which is also reported in other study [24].

From the above, it can be seen that the spillover effect on parents resulting from the environmental education of children is higher in children scoring highly in psychological factors such as subjective norm, attitude, expansion of interest and awareness of effectiveness - in other words, children with a high level of environmental concerns - and that this concern even impacts changes in the behavior of the child's family.

\section{Conclusions}

In this study, we implemented an environmental education program through classes in elementary and junior high schools that included visualization, and surveyed changes in the awareness and behavior of children. The program resulted in an increased awareness of effectiveness among children, whereas almost no statistically significant change was observed in other categories. It was indicated that the state of children's environmental concerns was already high and there were no rooms to be improved. At the same time, the parents' various energy-saving behaviors had increased, indicating a spillover effect on parents derived from the environmental 
education for children. The families who increased levels of interest and behavior in regard to global warming issues were impacted both by the fact that they heard about the benefits of energy savings from their children directly, and by changes in their children (an increased interest in global warming, implementation of energysaving behavior).

Model analysis showed that the psychological factors impacting energy-saving behavior in children themselves were: attitude, expectations from parents and expansion of interest, and that these formed their intention and contributed to behavior. While the children's awareness of effectiveness had no significant path to the behavior of children themselves, it had the significantly positive effects both on the values of energy-saving and various psychological factors of their parents. The behavior of children also had significant effect on improvement of parents' perception. Furthermore, the significant effect of the expectations from children on the parents' intentional and behavioral change was observed.

From this study, it is indicated that effective environmental education programs in school curriculums could promote whole family's energy-saving behaviors through children. In particular, it became clear that the higher the awareness of the child, the greater the spillover effect on the family as a result of education. This study focused on the program's short-term impact and further study still remains for understanding of long-term impact.

\section{Acknowledgements}

This study was undertaken as part of the "Formation of Low-carbon Bunkyo City by Inducing Voluntary Actions” project, which was included in the Japan Science and Technology Agency's Research Institute of Science and Technology for Society Project "Community-based Actions against Global Warming and Environmental Degradation". The authors would like to express sincere thanks to school teachers, children, students and others who cooperated in the implementation of the environmental education program and the subsequent surveys.

\section{References}

[1] Ministry of Education, Culture, Sports, Science and Technology (2008) Course of Study for Elementary Schools. Tokyo Shoseki, Tokyo.

[2] Ministry of Education, Culture, Sports, Science and Technology (2008) Course of Study for Elementary and Junior High Schools. Tokyo Shoseki, Tokyo.

[3] Rajecki, D.W. (1982) Attitudes: Themes and Advances. SinauerAssociates, Inc., Sunderland.

[4] Sajima, T., Takayama, J. and Yamashita, H. (2005) The Theory and Practice of Energy and Environmental Education. Kokudosha, Tokyo.

[5] Global Environmental Forum (2008) Institutional Study Report on Promotion of Environmental Education 2007. Global Environmental Forum, Tokyo.

[6] Global Environmental Forum (2009) Institutional Study Report on Environmental Conservation Activities and Environmental Education 2008. Global Environmental Forum, Tokyo.

[7] Eda, M. (2008) Current Situation and Problems of Energy Environmental Education in Japan. Energy Environmental Education for Sustainable Society, Kokudosha, 34-43.

[8] Hirose, Y. (2008) New Program of Environmental Education Based on Environmental Psychology. Journal of Environmental Information Science, 37, 36-40.

[9] Gamo, T. (2008) The Role of the Family in Eco-Conscious Behavior: Based on Case Studies of Environmental Education in the Grades-University Collaboration. Kyoto Women's University Academic Information Repository, 11, 29-49.

[10] Nakamura, M. (2003) Mothers’ Influence on the Development of Their Children’s Environmental Consciousness and Environment-Conscious Behavior. The Japanese Journal of Educational Psychology, 51, 76-85.

[11] Miyakawa, M., Ikatsu, H., Morooka, H., Hirota, Y., Habu, M. and Aoyama, I. (2009) Environmentally Conscious Behavior, Social Activity, Childhood Conditions, Domestic Environment, Experiences in Nature, Environmental Education. Proceedings of Kibi International University, School of International Environmental Management, 19, 37-46.

[12] Ajzen, I. and Fishbein, M. (1980) Understanding Attitude and Predicting Social Behavior. Englewood Chiffs, New Jersy.

[13] Ajzen, I. (1991) The Theory of Planned Behavior. Organizational Behavior and Human Decision Processes, 50, 179211. http://dx.doi.org/10.1016/0749-5978(91)90020-T

[14] Schwartz, S.H. (1977) Normative Influences on Altruism. In: Berkowitz, L., Ed., Advances in Experimental Social Psychology, Academic Press, New York, 221-279. 
[15] Stern, P.C., Dietz, T., Abel, T., Guagnano, G.A. and Kalof, L. (1999) A Value-Belief-Norm Theory of Support for Social Movements: The Case of Environmentalism. Human Ecology Review, 6, 81-97.

[16] Eisenberg, N. and Miller, P. (1987) The Relation of Empathy to Prosocial and Related Behaviors. Psycohological Bulletin, 101, 91-119. http://dx.doi.org/10.1037/0033-2909.101.1.91

[17] Hines, J.M., Hungerford, H.R. and Tomera, A.N. (1987) Analysis and Synthesis of Research on Responsible Pro-Environmental Behavior: A Meta-Analysis. The Journal of Environmental Education, 18, 1-8. http://dx.doi.org/10.1080/00958964.1987.9943482

[18] Doi, M. (2011) Research Review on Consciousness and Behavior in Environmental Education of Japan. Management Research of Hiroshima University, 11, 99-110.

[19] Kollmuss, A. and Agyeman, J. (2002) Mind the Gap: Why Do People Act Environmentally and What Are the Barriers to Pro-Environmental Behavior? Environmental Education Research, 8, 239-260. http://dx.doi.org/10.1080/13504620220145401

[20] Hayabuchi, Y. (2008) Spillover Effect of Environmental Education. Nakanishiya Shuppan, Kyoto.

[21] Ministry of Environment (2012) Questionnaire Survey of Consumrt. Ministry of Environment, Japan.

[22] Chan, K. (1998) Mass Communication and Pro-Environmental Behaviour: Waste Recycling in Hong Kong. Journal of Environmental Management, 52, 317-325. http://dx.doi.org/10.1006/jema.1998.0189

[23] Bamberg, S. (2003) How Does Environmental Concern Influence Specific Environmentally Related Behaviors? A New Answer to an Old Question. Journal of Environmental Psychology, 23, 21-32. http://dx.doi.org/10.1016/S0272-4944(02)00078-6

[24] Vaughan, C., Gack, J., Solorazano, H. and Ray, R. (2003) The Effect of Environmental Education on Schoolchildren, Their Parents, and Community Members: A Study of Interaenerational and Intercommunity Learning. The Journal of Environmental Education, 34, 12-21. http://dx.doi.org/10.1080/00958960309603489 